\section{Designing Communication Design}

Anders Sundnes Løvlie

IT University of Copenhagen

asun@itu.dk

\section{ABSTRACT}

Innovating in the field of new media genres requires methods for producing designs that can succeed in being disseminated and used outside of design research labs. This article uses the author's experiences with the development of university courses in communication design to address the research question: How can we design courses to give students the competencies they need to work as designers of new media? Based on existing approaches from UX design and other fields, I present a model that has demonstrated its usefulness in the development of commercial products and services. The model emphasises rapid techniques for user research and ideation; genre analysis; use of pitching and storytelling as a form of prototyping; and humanist methods for evaluation and critique.
Keywords

Communication design; genre; innovation; design education; media design; research through design; user experience design; ideation; NABC; lifecycle model.

\section{INTRODUCTION}

Many media scholars have argued for the need for constructive research in media and communication, to guide or spearhead the development of new media under concepts such as "communication design" (Morrison, 2011; Skjulstad, 2008; Storkerson \& Firedman, 2006), "media design" (Lunenfeld 2004; Nyre, 2014), "new media design" (Martinec \& van Leeuwen, 2009), "intervention" (Moulthrop, 2005), "aesthetic design” (Bolter, Engberg, \& MacIntyre, 2013) and "genre design" (Liestøl 2010). However, these contributions tend to frame design as a research activity, with little or no interest in
The Journal of Media Innovations 3.2 (2016), 72-87.

DOI: http://dx.doi.org/10.5617/jmi.v3i2.2486

(c) Anders Sundnes Løvlie 2016. developing new inventions to the point where they can successfully be implemented as new products or services and be used outside the research context. If innovation is "the implementation of [an] invention in a market or a social setting" (Storsul \& Krumsvik, 2013, p. 14), then a central challenge for genre innovation must be to develop methods for bridging the gap between inventing new media products or services, and implementing them. This entails seeing the form of design that is discussed here as not just a form of research, but also as a professional activity aimed at creating value for users and stakeholders. This article reports on a practical effort to develop this profession through the development of a master's-level specialisation course in communication design, addressing the following research question: how can we design courses to give students the competences they need to work as designers of new media? 
As noted by Donald Schön (1987), the introduction of a "reflective practicum" can be treated as a design problem (see also Simon, 1967). In other words, this article involves design on two levels, both as the object of study and the method for the study itself. I report on the iterative development of university-level courses as a practical, research through design investigation (Zimmerman, et al., 2007) into the future of communication as a discipline and profession.

Why is this a worthwhile endeavour? Let's consider the main stakeholders and their needs: employers, students, society, and academia. First, the most important group of employers is found in the media industries, who are currently undergoing a crisis. It is widely acknowledged that the need for innovation in the industry is great (Krumsvik \& Storsul, 2013; Svarre, 2011), which implies a need for graduates with the necessary competences to lead the development of new media products and services.

Second, for students who wish to work in the media industries, there is a need to seek out competences that meet the new demands of the media industries. Some argue that journalists need to understand code (Stavelin, 2015), and data-supported journalism seems to receive growing attention both in the industry and in education in journalism. However, when developing new media, manipulation of code and data is only one part of the picture. Attention must also be given to developing new designs that become meaningful for users and give them modes of participation that satisfy their needs (cf. Fagerjord, 2012). These are the kinds of problems designers address, and new media journalism will need to be able to incorporate designers' competencies in order to succeed.

Third, for society at large, media serve important functions for democracy and public discourse, and it is important to search for ways to improve the functioning of the media (cf. Nyre, 2009, 2014). Fourth, for academic researchers in particular, new design methods may open up fresh avenues for research into the possibilities inherent in new media technologies that is interesting simply for its potential to bring about new knowledge, whether framed as investigations into aesthetics (Bolter et al., 2013), rhetoric (Buchanan, 1985; Liestøl 2013), or similar areas.

In this special issue, these latter types of endeavours are referred to as "genre innovation". As Carolyn Miller has demonstrated, genres arise from social practices related to communicative needs (1984). When conducting genre innovation, it is es- sential to have methods for identifying these needs and for developing designs that meet the needs of the intended audience. The main contribution of this article is to offer a general, methodological model for conducting genre innovation, which is fit for use not only by researchers in academia, but also by students, designers and media professionals outside academia. This model also has the advantage that it has demonstrated its usefulness in practice for the development of both commercial and public products and services.

COMMUNICATION DESIGN IN RESEARCH AND HIGHER EDUCATION

The concept "communication design" is sometimes used as shorthand for "visual communication design", a term closely related to "graphic design" (Frascara, 2004; Yates \& Price, 2015). In this context, however, I use the term more broadly, to speak about the design and development of new media products or services based on research and competences drawn (at least in part) from media and communication studies. This includes the work of numerous scholars who use design as a mode of humanities-based media research (Bratteteig, 
Wagner, Morrison, Stuedahl, \& Mörtberg, 2010; Fagerjord, 2015; Liestøl, 2009; Løvlie, 2011b; Nyre, 2014), but it also includes work with media innovation and development outside of academia, in particular in the media industries.

Scholars in this field have sometimes reported on experiments conducted as part of university courses (Morrison, 2008; Nyre, 2015; Nyre, Bjørnestad, Tessem, \& Øie, 2012), but usually without offering general models that can be applied outside of the specific research programme which they serve. With the exception of Andrew Morrison (2001), existing discussions about design as a research method for media studies have largely avoided addressing knowledge and methods from neighbouring fields such as interaction design, user experience (UX) design, human-computer interaction (HCI) and service design. Neither Lars Nyre's proposed "media design method" (2014), Gunnar Liestøl's "genre design" (2013), Martinec \& van Leeuwen's language-based models (2009) nor Jay Bolter et al.'s "aesthetic design" (2013) give much room for user involvement, contradicting much of the consensus in contemporary design research. This seems rather counter-productive. Whatever the benefits of the new designs proposed by these researchers, those benefits will not reach a signifi- cant audience unless users perceive the new medium as understandable, meaningful and desirable. Increased attention to user-centric design methods would benefit also approaches driven by media and communication theory.

In the design field, many scholars have described design in various ways as a method for producing knowledge: as a form of science (Simon, 1969), a way of thinking (Rowe, 1987) or knowing (Cross, 2006), a "reflective conversation with the situation" (Schön, 1983), a process of meaningmaking and a fundamental part of what it is to be human (Krippendorff, 2006; Nelson \& Stolterman, 2003). Looking more specifically at design education, both Simon (1967) and Schön (1987) have treated the development of practice-oriented education as a design problem in and of itself. More recently, Dalsgaard et al. (2013) have proposed a model for "design argumentation" to bridge the divide between practice-based design teaching and theoretical academic traditions.

Commonly used textbooks in fields like interaction design (Löwgren \& Stolterman, 2007), UX design (Hartson \& Pyla, 2012) and service design (Stickdorn \& Schneider, 2011) have promoted holistic approaches which include consideration of many issues that overlap with media and com- munication studies, such as user (audience) ethnography, storytelling and aesthetics. The field of emotional design (Forlizzi, Disalvo, \& Hanington, 2003; Ho \& Siu, 2012) explores how to design for emotional reactions, mimicking a central concern for many media professions (cf. Hassenzahl, 2010).

Given this ever-widening array of approaches to design, one might ask whether there is a need for a new approach. What is special about communication design? Could we simply view it as UX design applied to a particular domain, that of the (new) media? I argue that there are at least three central characteristics of media that set this field apart from the IT industries in general, and complicate their use of established design methods: 1) tempo, 2) need for novelty and 3) relationship with the users (audience)

The tempo of production in parts of the media industries, in particular the news media, can be extreme. While typical IT development processes deal with systems that are developed over months or even years, a news journalist's process from idea generation to final product might be measured in hours or minutes. As remarked by some practitioners, this is a significant challenge when journalists are trying to collaborate with designers and IT professionals. For instance, the cross-disciplinary 
department for editorial development in the Danish broadcaster TV2 has developed a five-tempo model for classifying data-driven journalistic projects according to their production time: from "hyper mega fast" (minutes or hours) through "really fast" (tomorrow), "fast" (days or weeks), "not so fast" (weeks) to "this is a job for the CMS department" (weeks or months) (Bjerg, 2015). A recent study of Norwegian data journalists support the view that time is one of the most problematic factors for cross-disciplinary work involving editorial staff and IT developers (Karlsen \& Stavelin, 2014, p. 39).

Another characteristic of the media industries is the fact that many media products are consumed only once, or a few times. Films, TV shows, books, news items and any other product that takes the form of a "story", are perishables whose value relies on being new and unknown to the audience. Even more "reusable" formats like series, music and games often rely on their novelty for interest. This complicates the possibilities of user involvement in media production, in particular for products with high production tempo.

While focus groups and test audiences are widely used in film and TV production, approaches with a higher degree of audience involvement similar to design practices like co-creation and participatory design are hard to find. As shown by Fagerjord (2015), it may be problematic to directly apply methods for user-testing from other design fields. Carlson \& Wilmot (2006) and Hedemann (2010) provide accounts of growing realisations among media industry leaders about the need to improve their understanding of their audiences. Hedemann describes how the Norwegian public broadcaster NRK based the preparations for the 2010 Eurovision Song Contest Finale, a production aiming to reach more than 125 million viewers all over Europe, on an interview with one single viewer (Hedemann, 2010, pp. 50). This example is a striking demonstration of some media organisations' need for rapid and nimble methods for incorporating user research with the particular logic and tempo of media production.

The one-off character of many media products, combined with the high tempo and the lack of good methods for audience involvement, poses a significant problem for the development of new media, and contributes to the high-risk character of media production. One of the media industry's strategies for reducing this risk and balancing the need for novelty with the need for comprehension and predictability is by strategic use of genre. A genre con- tains a set of conventions that could both be seen as a collection of "design patterns" for the producers that represent known solutions to typical problems, and also as a set of audience expectations that are available to the producers to use as guidance for their production (cf. Miller, 1984; Müller 2013). Genre knowledge fills a function for media producers that in some ways parallels the function of user research and contextual inquiry in UX design. It is therefore not surprising that much work in the area of new media design, including this special issue, focuses on genre (Fagerjord, 2010; Liestøl 2013; Løvlie, 2011a).

The arguments above indicate a need for new methods and approaches to deal with the unique challenges involved in designing for media. In the following sections, I will show how we have attempted to meet these challenges through the iterative development of university courses in this field.

\section{METHOD: RESEARCH THROUGH DESIGN}

This article reports on the development of university courses as a design process producing a knowledge contribution, understood as a research through design approach (for a discussion of re- 
search through design approaches in media studies, see Løvlie, 2011b, pp. 27-49). According to Zimmerman et al. (2007), a research through design approach should be judged along four dimensions, of which two merit particular attention here: process and relevance.

The process is one which is not usually thought of as design, but rather as part of the pedagogical everyday practice of university teachers: writing and revising study programmes, course descriptions and syllabi; planning and teaching courses; preparing and grading exams; and so forth. In describing this as a design process I am building on broad definitions of design such as those discussed in the previous section, succinctly summarised by Nelson and Stolterman's concept "intentional change" (2003). The process has been iterative and spans teaching over five years in five different institutions (see Table 1 below). Given the nature and constraints of higher education, this has been an exploratory process where choices have been made and solutions tried out that have been based on our best available knowledge and creative exploration of the opportunities available, as well as our analysis and judgment as educators of what competences our students would need to succeed in the job market.
Schön describes the practice of design as a "reflective conversation with the situation", proceeding through a pragmatic process he terms "reflecting-in-action" (Schön 1983, 1987). The process with developing the courses discussed here can be described in a similar way. The process started with some initial ideas arising from research and the professional competences of my colleagues and myself, and proceeded from there through iterations involving analysis (of needs and connections within the study programs, of relevant course materials, of potential students, etc.), ideation and sketching (of course descriptions, syllabi, assignments and exercises, etc.), implementation in practice, and evaluation (formal and informal, by students, censors, administrators and faculty). Paraphrasing Schön, this is a complex design situation with many variables where any design choice may have both intended and unintended consequences: The designer "shapes the situation, (...) the situation 'talks back,' and he responds to the situation's back-talk" (Schön, 1983, p. 79). When courses are evaluated, revised and repeated, this sets up an iterative process in which approaches can be tried out and either discarded or refined along the way, building up a cumulated set of experiences and knowledge about productive solutions.
The relevance criterion states that design researchers must "articulate the preferred state their design attempts to achieve" (Zimmerman et al., 2007 , p. 500). In the case of university courses, this is a contentious question. How do we decide whether a course is good? University administrators might be inclined to point to measurable outcomes, such as scores in evaluation surveys among students or even, as in the Danish education system, to employment statistics for recent graduates. Many university teachers, on the other hand, often point to more qualitative ideals such as stimulating interest and critical reflection.

While most of the courses mentioned here have in fact been rated well by students, and increasingly so, student satisfaction is a poor indicator of quality (among other reasons: student satisfaction may correlate negatively with the level of challenges in the course). Instead, the main corrective to the teaching methods has been the student's success in achieving the intended learning outcomes of the courses, as judged by teachers and censors. When all or most of the students perform a given task poorly in assignments and exams, most likely there is something wrong in the teaching. If we change things around, and next semester's students perform better, most likely we have done something 
right. Relying on these forms of experiences sets up a pragmatic and qualitative process guided by reflection-in-action. This process has the significant benefit of producing insights that are relevant and applicable in practice. However, in order to supplement the author's own judgments with an external corrective, the discussion below will also include some data from evaluations by students and external partners.

\section{TEACHING COMMUNICATION DESIGN}

There is no room here for a complete chronological account of the process described above, but a brief outline is necessary. My work with developing courses in the area of communication design started after having finished my $\mathrm{PhD}$ research in that same area (Løvlie, 2011b). Starting out with teaching a cross-disciplinary course in media studies-based design (see overview of courses in Table 1 below), it quickly became clear to me that we were sorely lacking in methodology for this topic. After having spent three years in research arguing for the value in applying media and communications theory to the design of new media, I found myself face-to-face with students asking: how, specifically,
Table 1.

Overview of the courses on which this article is based.

\begin{tabular}{|c|c|c|c|}
\hline Course & Program $^{1}$ & Students & Semester \\
\hline Multimodal Design & B.A. Media Studies (UiO) & ca. 50 & Spring 2011 \\
\hline Mobile Media Design & M.A. Media Studies (UiO) & 13 & Fall 2011 \\
\hline Capstone Web Projects III & B.Sc. Web Development (GUC) & 8 & Fall 2012 \\
\hline Design Methods ${ }^{2}$ & B.Sc. Web Development (GUC) & 40 & Fall 2013 \\
\hline Design, Creativity and & M.Sc. Interaction Design (GUC) & 2013: 8 & Fall 2013 \\
\hline \multirow[t]{2}{*}{ Innovation ${ }^{2}$} & & 2014: 38 & Fall 2014 \\
\hline & & 2015: 26 & Fall 2015 \\
\hline Web Project I & B.Sc. Web Development (GUC) & 20 & Spring 2014 \\
\hline Mobile Communication II & M.Sc. Digital Design and Communication (ITU) & 9 & Fall 2014 \\
\hline Communication Design $I^{3}$ & M.Sc. Digital Design and Communication (ITU) & 55 & Spring 2015 \\
\hline Communication Design $\mathrm{II}^{4}$ & M.Sc. Digital Design and Communication (ITU) & 33 & Fall 2015 \\
\hline
\end{tabular}

$1 \mathrm{UiO}=$ University of Oslo, GUC = Gjøvik University College, ITU = IT University of Copenhagen.

2 Co-taught with Anders Fagerjord.

3 Co-taught with Janne Aagaard.

4 Co-taught with Janne Aagaard and Martina Mahnke. 
do we do that? Somewhat to my surprise, I found that the answers that my colleagues and I had to offer were disappointingly vague. I therefore made it a priority to search for methods from other disciplines that could be applied in this context, primarily from software development and interaction design. As I moved on to teaching students with a background closer to computer science, the challenge shifted due to the students' knowledge of methods from software development and interaction design, but the core problem remained: what are the specific methods that students of communication design should master?

Through the work with the courses listed in Table 1 above, and extensive collaboration with co-teachers and other colleagues (see acknowledgments), I have collected some approaches that answer this question, and assembled them in a provisional model. This model is implemented in the two courses I currently teach, which are the two modules of a specialisation called "Communication Design" in a cross-disciplinary M.Sc. programme in Digital Design and Communication. ${ }^{1}$

1 See information about the program at http://en.itu.dk/Programmes/MSc-Programmes/Digital-Design-and-Communication.

The Journal of Media Innovations 3.2 (2016)
The specialisation was offered for the first time in the spring semester 2015, aimed at "students who wish to work with the challenges of creating innovative new media products, either in the media industries or in communication roles in other types of organisations." In its first year, the specialisation received the second largest number of students in the programme and good student evaluations (see below).

In the second course of the specialisation, students worked with external partners from the media industries to develop new concepts and designs to meet the particular needs of the partner organisations. Based on the arguments presented above, the outcomes of these processes could be seen as a test of the value of the approach presented here: If the students were able to develop designs that the external partners deemed as valuable enough for them that they would develop them further into commercial products or services, this would be an indication that our model at least goes some way towards meeting the needs of both students and industry.

\section{THE COMMUNICATION DESIGN MODEL}

I will now first present the process leading to the overall model for our course, after which I will discuss each of the main elements in the model in some greater detail. When I first taught this topic, I had no clear model for the process, something which frustrated both the students and myself as it was difficult to communicate clearly to the students what precisely was expected of them, and what criteria their achievements would be judged against. Not surprisingly, the students' achievements in their exams varied widely, and may have reflected more closely their individual talents than the learning my colleagues and I had tried to convey.

In the next few courses I taught, I used the software development methodology Scrum (Schwaber \& Beedle, 2002) as a template for the process, using some imaginative re-interpretation to make it possible for design tasks to be sorted into "user stories" to be prioritised in "product backlogs" and "sprint backlogs". This was a significant improvement, and worked fairly well for students with technical backgrounds. However, in spite of our re-interpretation it quickly became clear that design tasks do not fit elegantly into Scrum: the agile mantra of "running code" has no obvious correspondence in design, and 


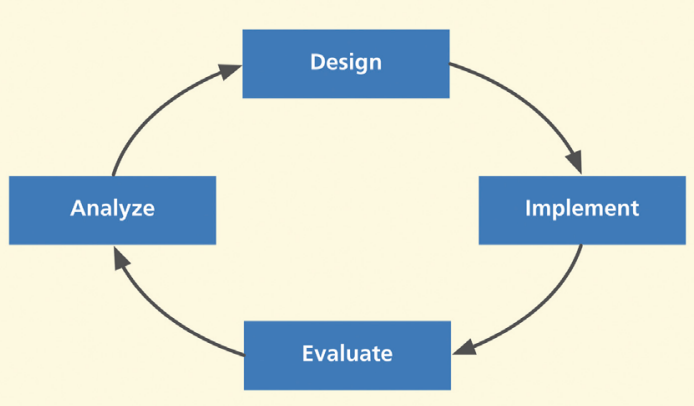

Figure 1: "The Lifecycle Model" (Hartson \& Pyla, 2012, p. 53).

the logic of user research, analysis and hermeneutic processes involved in understanding user needs is hard to divide into smaller tasks that can be easily re-prioritised and evaluated against a "definition of done" as demanded by the Scrum model. Although hybrid models exist for incorporating designers in Scrum-like processes (Beyer, 2010; Rogers, Sharp, \& Preece, 2011), they have little meaning when programming tasks are mostly (or wholly) absent from the process, as in most of our courses.

When given the chance to develop two new courses in design methods from scratch in the fall semester 2013, we opted instead to use Hartson and Pyla's (2012) "Lifecycle model" as our main approach. As shown in Figure 1: "The Lifecycle Model" (Hartson \& Pyla, 2012, p. 53) above, this model suggests a cyclical iteration through four main elements: analysis, design, implementation and evaluation.

This model made it significantly easier to communicate to the students which activities they should prioritise and how they should plan their projects. The resulting exams showed significant improvement over earlier courses (and incidentally, student satisfaction increased as well). However, the Lifecycle model also has shortcomings for our purposes. It puts little emphasis on ideation (organised under the opaque category "design"), which is problematic given our emphasis on the media industry's need for novelty, as described above. Further, the model tends to overemphasise work on usability testing, which is always important but has little meaning if it is not combined with a productive ideation process.

Therefore, from the fall semester of 2014, we have used a modified version of the Lifecycle model, combined with the NABC model (Carlson \& Wilmot, 2006) for innovation, as described in further detail below. The NABC model provides a lens through which to examine ideas for new designs at a very early stage and discuss weaknesses and strengths long before any prototyping or even sketching has begun. The model is a large improvement over previous alternatives, and it has the significant advantage of being used in some large media organisations (Hedemann, 2010). Using this model, students in our courses have been able to not only develop innovative concepts for new media applications, but also - as will be shown below they have been able to convince business partners to implement these concepts as commercial products and services.

Figure 2 illustrates our combined NABC/Lifecycle model approach. For greater conceptual clarity, I have renamed Hartson and Pyla's categories 'design" and 'implement' as 'ideation' and 'prototyping'. Under each main category are several keywords that point to specific techniques we have learned to be essential for students in this process. Below I discuss each of the four main categories in further detail. 


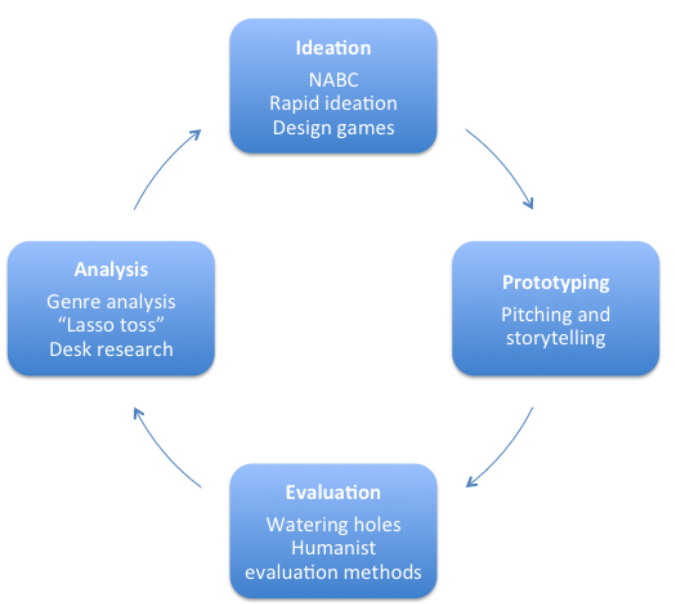

Figure 2: A "lifecycle model" for communication design.

\section{ANALYSIS: UNDERSTANDING THE USERS, UNDERSTANDING THE GENRE}

As in any other design discipline, understanding the user is essential - and a significant challenge for students. One of the main challenges students encounter is in combining an analysis of user needs with the creative process needed to develop novel designs. In order to help students with this challenge, we have employed the "lasso toss" technique described by Hedemann (2010, pp. 50-78), to ensure that students come face-to-face with at least one actual user early in the process, who can serve as a provisional persona. This method must be combined with careful desk research to identify and adjust to user needs in the broader population.

However, as described by Carlson and Wilmot (2006), understanding the user is only a small part of innovation; one must also understand the landscape of existing media - the competition. This is also a big challenge for students, and one which foregrounds the relevance of media and communication competence. Carlson and Wilmot point out how newcomers to the NABC method (see below) tend to focus too much on their own idea, and too little on the many alternatives that compete for the users' attention. We see the same tendency in our students, and often this appears as a form of "technology blindness": students propose an idea for a new solution that utilises one specific technology, and observing (often too optimistically) that no one else has used that same technology for that particular purpose, they conclude that there is no competition. However, if one broadens the perspective, it often becomes clear that users' needs may already be met by other solutions, often ones that employ older technologies or simpler solutions. Part of the challenge seems to be to shift the students away from an engineer's mind-set, in which one asks which technology would be best suited to solve a given problem, to a more designerly problem-setting approach, in which one prioritises reaching a deeper understanding of the problem and the ways in which the users are trying to satisfy their needs by existing means. This requires students to work hard to understand the role of different media and technologies in people's everyday lives - in other words, to adopt a core concern of media and communication studies. In particular, students need to be able to combine the quite concrete and practical know-how about how to construct new media, with the more abstract analytical skills required to understand what meaning a given solution may have for users, and whether this meaning entails something genuinely novel and valuable compared to existing alternatives.

I argued above that for media professionals, their knowledge and practical mastery of media genres help them understand and relate to the expectations of audiences. In particular, understanding genre is a good tool for understanding the competition, and positioning a new idea as an alternative to existing products. Hedemann (2010) tells the stories of a wide variety of development processes, where new concepts often are positioned as variations over existing genres. However, under- 
standing of genre is complicated when the medium itself is unstable and under ever-changing, rapid development, as is the case with most of the phenomena known as new media. As Müller points out, it may even be hard to identify when something is a new media genre, and when it is a new medium in its own right, as illustrated by scholarly debates about blogging (Müller, 2013, p. 255). This points to a need for developing better methods for genre analysis, which combine the rigor and analytical power needed to understand genres that cross modes, platforms and technologies, with the speed and ease needed to be able to support rapid ideation processes. This should be an important concern for future research and development.

\section{IDEATION: RAPID TECHNIQUES}

To address the need for speed and novelty when developing new media products, we have developed a strong focus in our courses on idea generation and concept development in fast, iterative processes. We use design games intended to help the students rapidly expand their view of the space of possibilities (Gray, Brown, \& Macanufo, 2010), in combination with the NABC model mentioned above.
Through the iterations of our courses we have seen that one of the largest challenges for the students is to produce ideas that are different and new, which innovate on the level of the meaning and role the design should have for the user. In other words: how can one invent designs that do new things, not just doing the same things in a slightly improved manner? Given the importance of novelty for the media industries, these are problems of particular importance for communication design.

Furthermore, it is important to work iteratively and fast because it is difficult for students to grasp what it entails to work with idea development. Anyone can fill in the blanks in the NABC model with some bullet points in a few minutes, and hey! You have yourself a new media concept. For an inexperienced reader, it is not always easy to see how much work has gone into a well-developed value proposition based on months of research, precisely because a good concept should be possible to convey with just a few sentences. Therefore, it is easy for students to underestimate the amount of work that needs to be done: user research, analysis, prototyping and testing in iterative loops, taking into account expanding knowledge and shifting focus throughout the process. We have found that students need to gain practical experience and receive critical feedback as fast as possible. Like Silicon Valley entrepreneurs, students need to fail early and fail often.

\section{PROTOTYPING: PITCHING AND} STORYTELLING

The importance of being able to pitch a new idea for stakeholders is one of the strong connections between the design disciplines and practical media production. Just as scriptwriters and directors in film and TV need to be able to pitch their ideas for new productions, and newspaper journalists need to know how to sell a story in a few sentences to their editors, colleagues (and ultimately, their readers), pitching is essential for designers who want their ideas to be realised. A pitch, as any other presentation, can be seen as a form of storytelling (Abela, 2013; Arola, Sheppard, \& Ball, 2014; Carlson \& Wilmot, 2006; Hedemann, 2010). It can also be regarded as a prototype, in the sense of the word used by Houde and Hill (1997); one that is typically focused on the "role" of the design rather than its "look and feel" or implementation. Creating a pitch which needs to be delivered within strict time constraints forces students to prioritise their material 
and focus on that which is most important, in order to show that they have identified an important user need for which they can deliver a unique solution.

In the first course of the Communication Design specialisation, the students go through several iterations of developing a concept, and a pitch to be delivered in a competition with the rest of the class. Practicing their pitches in front of other students gives them a very direct experience with what storytelling techniques work well for this kind of purpose. It forces students to think about their designs in terms of what Krippendorff calls "paths from the present toward desirable futures" (Krippendorff, 2006, sec. 1.4.2.), and how to convey those paths to stakeholders and users. As Krippendorff shows, developing designs through stories is central for many forms of design. Given the importance of storytelling in the media industries, storytelling will be of particular importance for communication design. There is a need for more research into effective methods for prototyping through storytelling.

\section{EVALUATION}

Students need to quickly reach the point where their ideas can be examined critically. The NABC model prescribes a framework for this, called "watering holes". In our courses this usually takes the form of group supervision, where we gather two or three groups and ask them to pitch their ideas and receive criticism from each other and the teachers. As a teacher, one must find a balance between encouraging and motivating students, and critiquing their work. The students must learn to adapt a similar balance: creating an open and inclusive atmosphere for brainstorming, but also making sure to include moments of critical inspection of their own ideas and designs. We find that student groups tend to have a harder time with the latter than the former, perhaps because of group dynamics leading to group think. Watering holes is a tool to combat this tendency.

As projects move from the early idea stages to more advanced stages where sketches and prototypes are produced, it becomes important to test concepts on users. As described by Fagerjord (2015), methods for user testing from other design fields can be used to evaluate certain aspects of a design, but there is also a need for more specific methods in evaluating the meaning of a text (or a genre prototype) for a user. Fagerjord suggests a set of "humanist evaluation methods", including Krippendorff's semantic analysis, "within-subject
A/B tests" and expert evaluation. However, more work is needed here, in particular with a view to developing a repertoire of methods which can be used for different types of products, and accommodating the need for a high-paced process.

\section{EVALUATIONS OF THE TEACHING}

Above I have described many of the challenges that students face and our solutions for overcoming them, based on our own judgments about what the students need and which solutions help them achieve good results. The students have also been able to voice their opinions about our courses through course evaluations, typically one or several informal evaluations conducted by the teachers early in the semester and one formal, anonymous evaluation towards the end of the semester.

For the two courses in communication design at the IT University, student evaluations are publicly available from the university's website. ${ }^{2}$ When students in the 2015 cohort were asked to rate their agreement with the statement "I am happy about

2 See http://en.itu.dk/About-ITU/Organisation/Facts-and-Figures/ Quality-and-Educational-Environment/Course-Evaluation. 


\section{Table 2.}

Answers from external partners to the question "Have you chosen to move forward with the students' ideas/projects in your organisation?”

\begin{tabular}{ll}
\hline Answer & Frequency \\
"Yes, we are moving forward" & 0 \\
"Yes, we will move forward with & 2 \\
parts of the project" & \\
"We are considering whether to & 4 \\
move forward" & \\
"No, we are not moving forward" & 0 \\
"Other" & 0 \\
Total & 6
\end{tabular}

$(N=6)$. All quotes from this survey are my translations from Danish. this course" on a scale from 1- 6 (where 6 indicated total agreement) the spring course received a score of 4,72 (response rate: 40/55), and the fall course 4,31 (response rate: $13 / 33$ ). For the statement "I think the course is relevant for my future job profile", the score was 4,90 and 4,77 , respectively. While these figures show encouraging levels of student satisfaction for a specialisation in its first iteration at this university, we do not hold student satisfaction as the best indicator of course quality.

For the Fall 2015 course, we conducted a simple evaluation survey among the 6 business partners for whom students worked during the course. The survey was conducted using the online service surveymonkey.com 1-2 weeks after the students had presented their final designs. Responses were anonymous and the response rate was $6 / 6$. Asked whether they would move forward to implement the students' designs, 2 partners at this early date answered partially affirmative and 4 said they were still considering it (see Table 2). One partner (the house and gardening magazine Idényt) announced already at the student presentation that they had concrete plans for a commercial implementation of the students' project, with a deadline set ca. 6 months after the end of the course (May 2016). Shortly before the deadline for this article another partner (the online news magazine Zetland) publicly announced their plans for developing an online comments feature similar to the kind proposed by students (Korsgaard, 2016). Answers to other questions and free-text comments in the survey were overwhelmingly positive.

Several of our master's thesis students have also used elements of the model described here to develop designs for external partners. At least two of these projects are currently being developed for commercial implementation by these external partners (the Mofibo e-book service, as well as Copenhagen Airport in partnership with the city of Copenhagen)

\section{CONCLUDING REMARKS}

The preceding discussion has outlined a set of methods and techniques that are particularly useful for communication design, summarised as a combination of the NABC model and Hartson and Pyla's Lifecycle model. The model shown in Figure 2: A "lifecycle model" for communication design. (above) is greatly simplified and is far from a complete toolbox for prospective communication designers. However, it is my hope that it can serve 
as a starting point for a process towards developing communication design to a design sub-discipline which meets the needs of both the media industry, students, society and media research. The fact that students in our courses have been able to use this model to develop designs that are being implemented as commercial products and services by external partners gives an indication that the model is effective.

An important task for future research should be to increase our knowledge of the design work that takes place in the media industries. The media industries are well aware of the need to innovate, and the work being done through collaborations between designers, media and IT professionals on a daily basis is an important source of knowledge about how to best design new media products, and thereby, to conduct genre innovation. Therefore, empirical studies of work practices and methods in design and development departments of media organisations should be an important focus for research in communication design.

So far, communication design. What is the relevance of this approach for genre innovation? One does not design genres; one designs artefacts (e.g., new media systems or "texts"), which become genres only if and when they are used and imitated in a wider public. In other words, the transformation a new media design must go through in order to become a genre parallels the transformation of an invention into an innovation: It must be implemented and disseminated and used by people outside the context of the invention. However, the word "genre" indicates a level of ambition higher than "innovation": a new design may be considered an innovation as soon as it is being disseminated and used sufficiently widely, whereas it is not a genre until other designs are made that imitate the first. No separate method can be devised for reaching this highest level of ambition, since it depends on the actions of others who are not connected with the designers of the original. However, one may reasonably assume that successful designs are likely to be imitated; so even if we leave aside the discussion of whether it would be meaningful at all to talk about a methodology for 'genre innovation', we can safely assume that in order to effect this kind of innovation one needs to do communication design well. The model presented in this article is one suggestion for how to achieve this goal, and the experiences of teachers and students in the courses described provide some evidence for the viability of the model. Further research and practical experiences may tell us if the designs that are made by use of this model will succeed not only as design projects, but as real-world innovations, and ultimately as new media genres.

\section{ACKNOWLEDGEMENTS}

Above I have often used first person singular, because the argument in this article (and any shortcomings in it) is my responsibility. However, much of the course development, the teaching and the ideas that have resulted in this article have come about through extensive collaboration with good colleagues, in particular Anders Fagerjord, together with whom I developed and taught several courses in the period 2010-2016; as well as Janne Aagaard, who has co-taught and co-developed the Communication Design specialisation with me at the IT University of Copenhagen from 2014 and onwards. Great thanks also go to the rest of my colleagues at the IT University of Copenhagen and the Norwegian University of Science and Technology at Gjøvik, who have contributed in countless ways. 


\section{REFERENCES}

Abela, A. (2013). Advanced presentations by design: Creating communication that drives action (2nd edition). San Francisco, CA: Pfeiffer.

Arola, K. L., Sheppard, J., \& Ball, C. (2014). Writer/ designer: A guide to making multimodal projects. Boston, MA: Bedford/St. Martin's.

Beyer, H. (2010). User-centered agile methods. San Rafael, CA: Morgan and Claypool Publishers.

Bjerg, M. (2015). Redaktionel udvikling på tv2.dk (Editorial development in tv2.dk). Presented at the Nordic data journalism conference, 30-31 January 2015. Ålesund, Norway.

Bolter, J. D., Engberg, M., \& MacIntyre, B. (2013). Media studies, mobile augmented reality, and interaction design. Interactions, $X X(1), 36-45$.

Bratteteig, T., Wagner, I., Morrison, A., Stuedahl, D., \& Mörtberg, C. (2010). Research practices in digital design. In I. Wagner, T. Bratteteig, \& D. Stuedahl (Eds.), Exploring digital design: Multi-disciplinary design practices (pp. 17-54). London: SpringerVerlag.

Buchanan, R. (1985). Declaration by design: Rhetoric, argument, and demonstration in design practice. Design Issues, 2(1), 4-22. http://doi. org/10.2307/1511524
Carlson, C. R., \& Wilmot, W. W. (2006). Innovation The five disciplines for creating what customers want. New York: Crown Business.

Cross, N. (2006). Designerly ways of knowing. London: Springer-Verlag. Retrieved from http://link. springer.com/10.1007/1-84628-301-9

Dalsgaard, P., Dindler, C., \& Fritsch, J. (2013). Design argumentation in academic design education. In Nordes 2013: Experiments in design research (Vol. 5). Malmö University: NORDES - Nordic Design Research. Retrieved from http://www.nordes.org/ opj/index.php/n13/article/view/331

Fagerjord, A. (2010). After convergence: YouTube and remix culture. In J. Hunsinger, L. Klastrup, \& M. Allen (Eds.), International handbook of internet research (pp. 187-200). Dordrecht: Springer Netherlands.

Fagerjord, A. (2012). Design som medievitenskapelig metode (Design as method for media studies). Norsk medietidsskrift, 19(3), 198-215.

Fagerjord, A. (2015). Humanist evaluation methods in locative media design. The Journal of Media Innovations, 2(1), 107-122.

Forlizzi, J., Disalvo, C., \& Hanington, B. (2003). On the relationship between emotion, experience and the design of new products. The Design Journal, 6(2), 29-38. http://doi. org/10.2752/146069203789355507
Frascara, J. (2004). Communication design: Principles, methods, and practice. New York: Allworth Press.

Gray, D., Brown, S., \& Macanufo, J. (2010).

Gamestorming: A playbook for innovators, rulebreakers, and changemakers (1st edition). O'Reilly Media.

Hartson, R., \& Pyla, P. (2012). The UX book: Process and guidelines for ensuring a quality user experience. Waltham: Morgan Kaufmann.

Hassenzahl, M. (2010). Experience design: Technology for all the right reasons. Synthesis Lectures on $\mathrm{Hu}$ man-Centered Informatics, 3(1), 1-95. http://doi. org/10.2200/Soo261ED1Vo1Y201003HCIoo8

Hedemann, O. (2010). Idéutvikling i mediehuset (Ideation for media). Fredrikstad: IJ-forlaget.

Ho, A. G., \& Siu, K. (2012). Emotion design, emotional design, emotionalize design: A review on their relationships from a new perspective. The Design Journal, 15(1), 9-32. http://doi.org/10.2752/17563061 2X13192035508462

Houde, S., \& Hill, C. (1997). What do prototypes prototype? In M. Helander, T. Landauer, \& P. Prabhu (Eds.), Handbook of human-computer interaction (2nd ed.). Amsterdam: Elsevier Science B. V.

Karlsen, J., \& Stavelin, E. (2014). Computational journalism in Norwegian newsrooms. Journalism Practice, 8(1), 34-48. http://doi.org/10.1080/17512786 2013.813190 
Korsgaard, L. (2016, March 14). Træd indenfor i Zetland (Step inside Zetland). Zetland. Copenhagen. Retrieved from https://www.zetland.dk/historie/ sekXrJ9J-a8DEYXaM-c1728

Krippendorff, K. (2006). The semantic turn: A new foundation for design. Boca Raton: CRC Press.

Krumsvik, A. H., \& Storsul, T. (Eds.). (2013). Media innovations: A multidisciplinary study of change. Göteborg: Nordicom.

Liestøl, G. (2009). Situated simulations: A prototyped Aaugmented reality genre for learning on the iPhone. International Journal of Interactive Mobile Technologies, 3(Special Issue IMCL2009), 24-28.

Liestøl, G. (2010). On mobility, localization and the possibility of digital genre design. In I. Wagner, $\mathrm{T}$. Bratteteig, \& D. Stuedahl (Eds.), Exploring digital design: Multi-disciplinary design practices (pp. 171-188). London: Springer.

Liestøl, G. (2013). Topics of innovation. Towards a method of invention and innovation in digital media design. In T. Storsul \& A. Krumsvik (Eds.), Media innovations: A multidisciplinary study of change (pp. 61-74). Göteborg: Nordicom

Løvlie, A. S. (2011a). Locative literature: experiences with the textopia system. International Journal of Arts and Technology, 4(3), 234-248. http://doi. org/10.1504/IJART.2011.041479
Løvlie, A. S. (2011b). textopia: experiments with locative literature (Ph.D. dissertation). University of Oslo, Oslo.

Löwgren, J., \& Stolterman, E. (2007). Thoughtful interaction design: A design perspective on information technology. Cambridge, MA: The MIT Press.

Lunenfeld, P. (2004). Media design: new and improved without the new. New Media \& Society, 6(1), 65-70.

Martinec, R., \& van Leeuwen, T. (2009). The language of new media design: Theory and practice (1 edition). London; New York: Routledge.

Miller, C. (1984). Genre as social action. The Quarterly Journal of Speech, 7o(2), 151-167.

Morrison, A. (2001). electracies: investigating transitions in digital discourses \& multimedia pedagogies in higher education: case studies in academic communication from Zimbabwe. (Ph.D. dissertation). University of Oslo, Oslo.

Morrison, A. (2008). Stretching multiliteracies: production-based education \& new media. Nordic Journal of Digital Literacy, 3(03), 179201.

Morrison, A. (2011). Inside multimodal composition. New York: Hampton Press.
Moulthrop, S. (2005). After the last generation: Rethinking scholarship in the days of serious play (pp. 208-215). Presented at the Sixth Digital Arts \& Culture Conference, 1-3 December 2005. Copenhagen: IT University of Copenhagen. Retrieved from http:// iat.ubalt.edu/moulthrop/essays/dac2005.pdf

Müller, K. (2013). Innovation and the genre-platform model. In T. Storsul \& A. Krumsvik (Eds.), Media innovations: A multidisciplinary study of change (pp. 255-273). Göteborg: Nordicom.

Nelson, H. G., \& Stolterman, E. (2003). The design way: Intentional change in an unpredictable world. Englewood Cliffs, NJ: Educational Technology Publications.

Nyre, L. (2009). Normative media research. Moving from the ivory tower to the control tower. Nordicom Review, 3o(2), 3-17.

Nyre, L. (2014). Media design method: Combining media studies with design science to make new media. The Journal of Media Innovations, 1(1), 86-109.

Nyre, L. (2015). Designing the Amplifon. A locative sound medium to supplement $\mathrm{DAB}$ radio. The Journal of Media Innovations, 2(2), 58-73. 
Nyre, L., Bjørnestad, S., Tessem, B., \& Øie, K. V. (2012). Locative journalism: designing a location-dependent news medium for smartphones. Convergence:

The International Journal of Research into New Media Technologies, 18(3), 297-314. http://doi. org/10.1177/1354856512441151

Rogers, Y., Sharp, H., \& Preece, J. (2011). Interaction design: Beyond human - computer interaction. Chichester, UK: John Wiley \& Sons.

Rowe, P. G. (1987). Design thinking. Cambridge, MA: The MIT Press.

Schön, D. A. (1983). The reflective practitioner: How professionals think in action. Aldershot, UK: Ashgate.

Schön, D. A. (1987). Educating the reflective practitioner: Toward a new Design for teaching and learning in the professions. Chichester, UK: Wiley.

Schwaber, K., \& Beedle, M. (2002). Agile software development with Scrum. Upper Saddle River, NJ: Prentice Hall.

Simon, H. (1969). The sciences of the artificial. Cambridge, MA: The MIT Press.
Simon, H. A. (1967). The business school: a problem in organizational design. Journal of Management Studies, 4(1), 1-16. http://doi. org/10.1111/j.1467-6486.1967.tboo569.x

Skjulstad, S. (2008). Mediational sites: A communication design perspective on websites (Ph.D. dissertation). University of Oslo, Oslo.

Stavelin, E. (2015, August 17). Hvorfor utdanner vi journalister som ikke kan programmere? (Why are we educating journalists who do not know programming?) Retrieved from http:// voxpublica.no/2015/o8/hvorfor-utdanner-vijournalister-som-ikke-kan-programmere/?utm source=twitterfeed\&utm_medium=twitter

Stickdorn, M., \& Schneider, J. (2011). This is service design thinking: Basics, tools, cases. Hoboken, NJ: John Wiley \& Sons. Retrieved from http://eu.wiley. com/WileyCDA/WileyTitle/productCd-1118156307. html

Storkerson, P. (2006). How to develop basic research in communication design. In Proceedings of WonderGround - 2006 Design Research Society International Conference 1-4 November 2006, Lisbon.
Storsul, T., \& Krumsvik, A. H. (2013). What is media innovation? In T. Storsul \& A. H. Krumsvik (Eds.), Media innovations: A multidisciplinary study of change (pp. 13-26). Göteborg: Nordicom.

Svarre, P. (2011). Den perfekte storm (The perfect storm). København: Gyldendal.

Yates, D., \& Price, J. (2015). Communication design: insights from the creative industries. New York: Fairchild Books AVA.

Zimmerman, J., Forlizzi, J., \& Evenson, S. (2007). Research through design as a method for interaction design research in HCI. In Proceedings of the SIGCHI Conference on Human Factors in Computing Systems (pp. 493-502). New York, NY, USA: ACM. http://doi.org/10.1145/1240624.1240704 